Supporting Information

Highly selective conversion of glycerol to formic acid over a synergistic Au/phosphotungstic acid catalyst under nanoconfinement

Yi-Tzu Lin ${ }^{\mathrm{b}}$, Jingling Yang, ${ }^{\mathrm{a}, *}$, Chung-Yuan $\mathrm{Mou}^{\mathrm{b}, *}$

a School of Environment, Jinan University, Guangzhou 510632, China

${ }^{\mathrm{b}}$ Department of Chemistry, National Taiwan University, Taipei 10617, Taiwan

Number of pages: 8

Number of tables: 2

Number of figures: 5

* Corresponding author.

E-mail address: yangj1@jnu.edu.cn (J. L. Yang), cymou@ntu.edu.tw (C. -Y. Mou) 


\section{Synthesis of samples}

Synthesis of mesoporous silica nanoparticles (MSN): The fabrication of mesoporous silica nanoparticles (MSN) was conducted according to our previous article. ${ }^{23}$ Typically, the mixed emulsion composed of cetyltrimethylammonium bromide $(\mathrm{CTAB}) / \mathrm{H}_{2} \mathrm{O} /$ decane/ethanol, with the adding amount of $0.2 \mathrm{~g}, 80.0 \mathrm{~g}, 600 \mu \mathrm{L}$, and $6.0 \mathrm{~g}$, respectively, was stirred at $50^{\circ} \mathrm{C}$ for $12 \mathrm{~h}$, in which decane acts as a pore expanding agent. Afterwards, $1.5 \mathrm{~g}$ of ammonia solution (35 wt.\%) and $1.67 \mathrm{~mL}$ of tetraethyl orthosilicate (TEOS)/ethanol solution (20\% v/v) were added dropwise into the mixed solution, respectively. The resulted mixture was stirred at $50^{\circ} \mathrm{C}$ for $1 \mathrm{~h}$ followed by aging at $50^{\circ} \mathrm{C}$ for $20 \mathrm{~h}$. Then, the obtained solution mixture was filtered with a qualitative filter paper (Advantec) to remove side products that formed at the oil-water interfaces. The filtered solution was then hydrothermally treated at $80^{\circ} \mathrm{C}$ for $24 \mathrm{~h}$. To remove the residual organic surfactants, the collected sample was dispersed in $30 \mathrm{~mL}$ of hydrochloric acid/ethanol solution $(5.0 \mathrm{mg} / \mathrm{mL})$ at $50^{\circ} \mathrm{C}$ for $16 \mathrm{~h}$ under constant stirring followed by centrifugation and sonication with ethanol five times to recover the MSN. Finally, the as-synthesized MSN were dispersed in ethanol for preservation. 
Synthesis of Au/MSN: $10.0 \mathrm{mg}$ of as-prepared APTMS-functionalized MSN

was suspended in $6 \mathrm{~mL}$ of $\mathrm{HAuCl}_{4}$ aqueous solution $\left(1 \times 10^{-4} \mathrm{~mol} / \mathrm{L}\right)$ and

stirred at $25^{\circ} \mathrm{C}$ for $30 \mathrm{~min}$. Then, with an introduction of $0.6 \mathrm{~mL}$ of $\mathrm{NaBH}_{4}$

solution (0.02 mol/L) and stirred for $1 \mathrm{~min}$, and kept aging in the solution for 1

h. Subsequently, the nanocomposites were rinsed with water and

vacuum-dried. The as-prepared sample was labeled as Au/MSN.

Table S1. Effect of $\mathrm{H}_{2} \mathrm{O}_{2}$ concentration on glycerol oxidation in Au-PTA/MSN/ $\mathrm{H}_{2} \mathrm{O}_{2}$ system.

\begin{tabular}{|c|c|c|c|c|c|c|c|c|}
\hline \multirow{3}{*}{ Catalyst } & \multirow{3}{*}{$\begin{array}{l}\text { Molar ratio of } \\
\text { glycerol: } \mathrm{H}_{2} \mathrm{O}_{2}\end{array}$} & \multirow{3}{*}{ Conv. $(\%)$} & \multicolumn{4}{|c|}{ Selectivity of products $(\%)$} & \multirow{2}{*}{\multicolumn{2}{|c|}{$\begin{array}{c}\text { Total } \\
\text { organic product }\end{array}$}} \\
\hline & & & \multirow{2}{*}{ FA } & \multirow{2}{*}{ GA } & \multirow{2}{*}{$\begin{array}{c}\text { GLYA } \\
\text { D }\end{array}$} & \multirow{2}{*}{ DHA } & & \\
\hline & & & & & & & & $(\%)$ \\
\hline \multirow{3}{*}{ Au-PTA/MSN } & $1: 3$ & 20.2 & 61.8 & 10.3 & 10.0 & 1.7 & & 83.8 \\
\hline & $1: 5$ & & 33.6 & 79.2 & 4.1 & - & - & 83.3 \\
\hline & $1: 1$ & & 53.4 & 43.9 & 22.7 & - & - & 66.6 \\
\hline
\end{tabular}

Table S2. Content of Au and W elements in MSN, PTA/MSN and Au-PTA/MSN.

\begin{tabular}{ccc}
\hline Sample & Auwt.\% & W wt.\% \\
\hline Au-PTA/MSNa & 1.34 & 48.22 \\
\hline
\end{tabular}

${ }^{a}$ Catalyst after three cycle of use. 


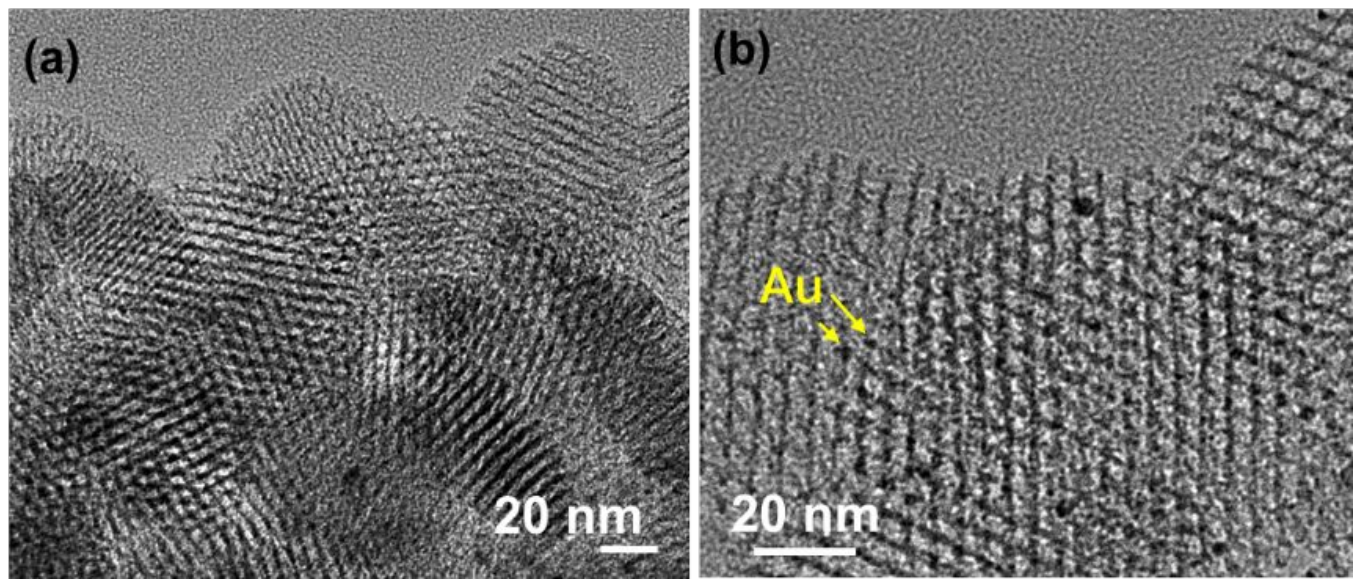

Figure S1. (a) TEM image and (b) High-resolution TEM image of Au/MSN. 


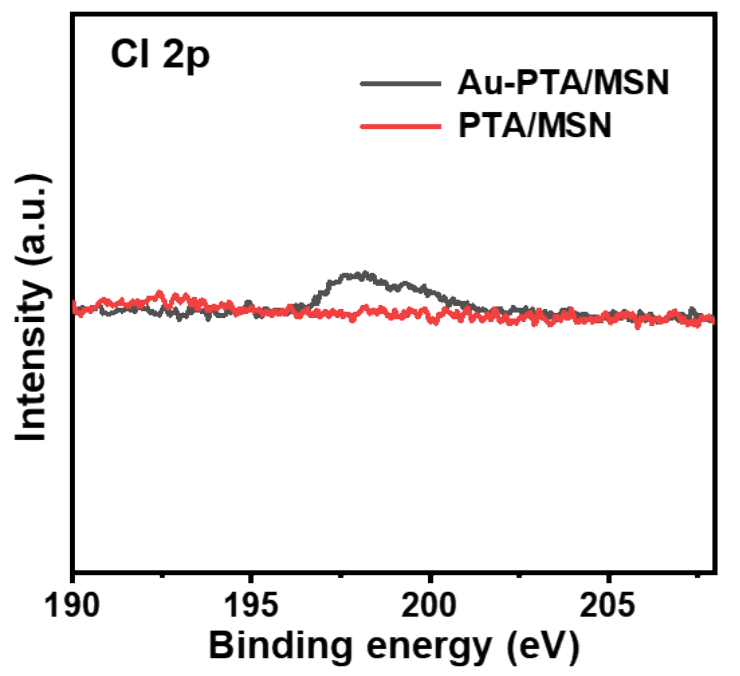

Figure S2. High-resolution XPS spectra of $\mathrm{Cl} 2 \mathrm{p}$ of Au-PTA/MSN. 


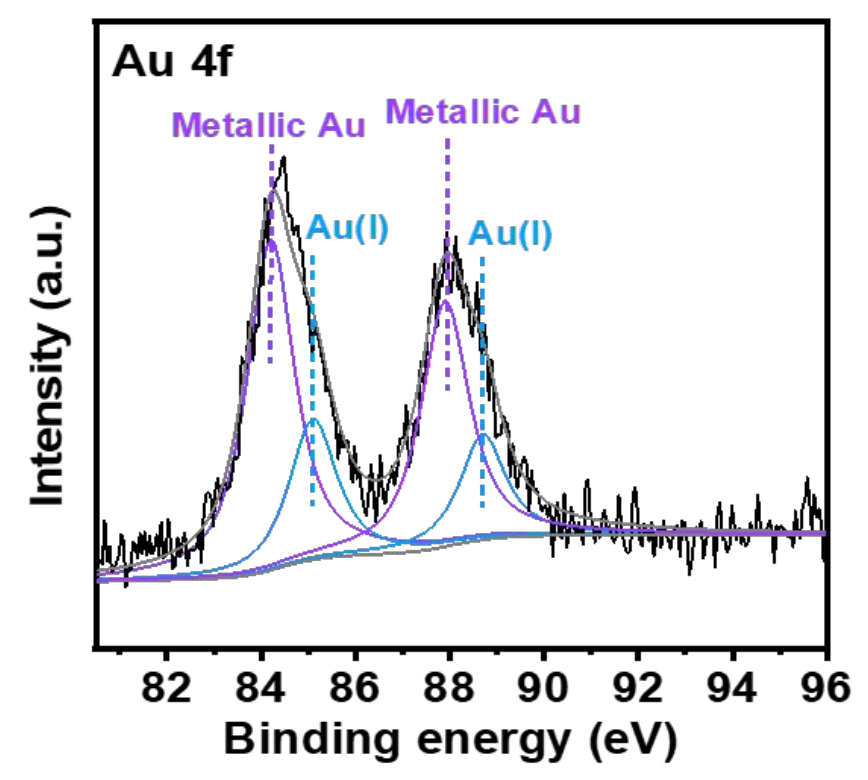

Figure S3. High-resolution XPS spectra of Au $4 \mathrm{f}$ of $\mathrm{Au} / \mathrm{MSN}$. 


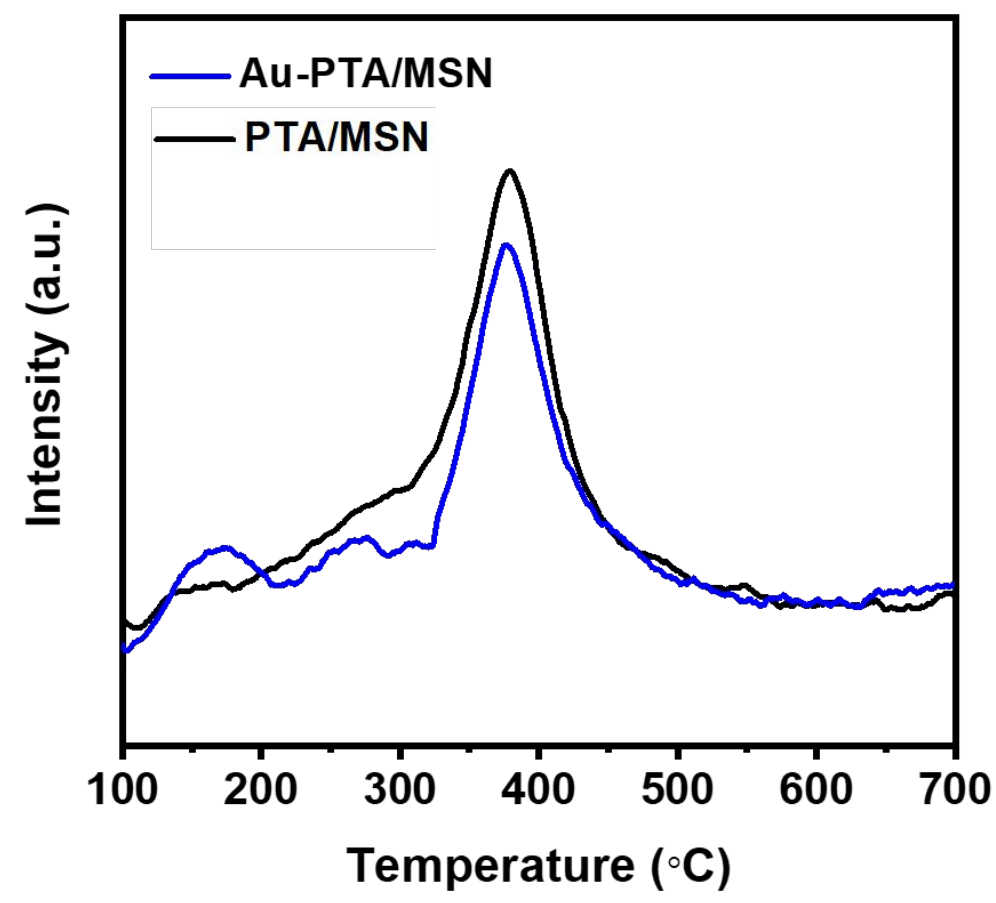

Figure S4. $\mathrm{NH}_{3}$-TPD profiles of PTA/MSN, Au-PTA/MSN, and pure PTA. 


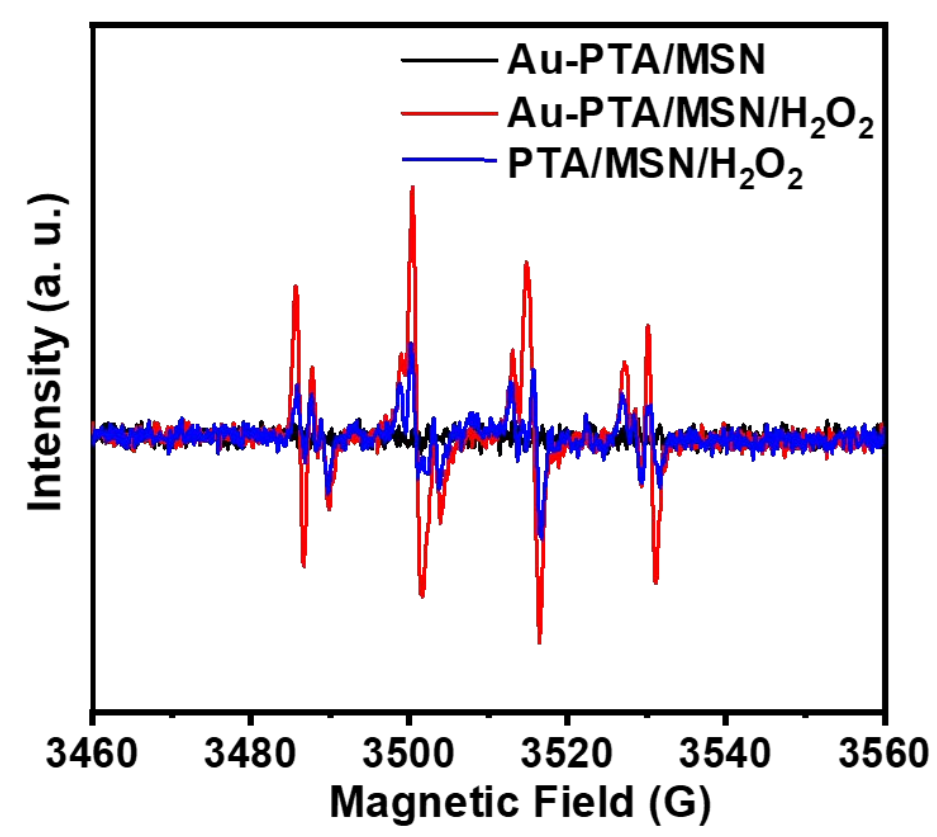

Figure S5. DMPO spin-trapping ESR spectra of Au-PTA/MSN and PTA/MSN in deionized water dispersion for DMPO - $\bullet \mathrm{OH}$ with $\mathrm{H}_{2} \mathrm{O}_{2}$ and Au-PTA/MSN in the absence of $\mathrm{H}_{2} \mathrm{O}_{2}$, respectively. 